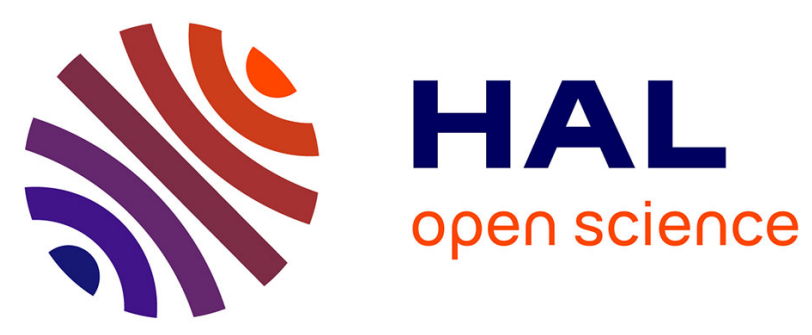

\title{
Pyrolysis of wood impregnated with phosphoric acid for the production of activated carbon: Kinetics and porosity development studies
}

\author{
Idriss Ahmed Hared, Jean-Louis Dirion, Sylvain Salvador, Marcel Lacroix,
} Sébastien Rio

\section{To cite this version:}

Idriss Ahmed Hared, Jean-Louis Dirion, Sylvain Salvador, Marcel Lacroix, Sébastien Rio. Pyrolysis of wood impregnated with phosphoric acid for the production of activated carbon: Kinetics and porosity development studies. Journal of Analytical and Applied Pyrolysis, 2007, 79 (1-2), pp.101105. 10.1016/j.jaap.2006.12.016 . hal-01718079

\section{HAL Id: hal-01718079 \\ https://hal.science/hal-01718079}

Submitted on 1 Jun 2018

HAL is a multi-disciplinary open access archive for the deposit and dissemination of scientific research documents, whether they are published or not. The documents may come from teaching and research institutions in France or abroad, or from public or private research centers.
L'archive ouverte pluridisciplinaire HAL, est destinée au dépôt et à la diffusion de documents scientifiques de niveau recherche, publiés ou non, émanant des établissements d'enseignement et de recherche français ou étrangers, des laboratoires publics ou privés. 


\title{
Pyrolysis of wood impregnated with phosphoric acid for the production of activated carbon: Kinetics and porosity development studies
}

\author{
Idriss Ahmed Hared ${ }^{\text {a,*, Jean-Louis Dirion }}{ }^{\text {a }}$, Sylvain Salvador ${ }^{\text {a }}$, \\ Marcel Lacroix ${ }^{\mathrm{b}}$, Sebastien Rio ${ }^{\mathrm{a}}$ \\ ${ }^{a}$ LGPSD, Ecole des Mines d'Albi-Carmaux, Campus Jarlard 81013 Albi, France \\ ${ }^{\mathrm{b}}$ Université de Sherbrooke, Faculté de Génie, Sherbrooke, Québec, Canada J1K 2RI
}

\begin{abstract}
The pyrolysis of impregnated wood for the production of activated carbon is investigated. Laboratory experiments are performed in a TG for heating rates of $10{ }^{\circ} \mathrm{C} / \mathrm{min}$ and $20^{\circ} \mathrm{C} / \mathrm{min}$ and a mathematical model for the kinetics of the pyrolysis process is developed and validated. The effect of the temperature and of the time duration of the pyrolysis process on the specific surface of the activated carbon is examined on the basis of experiments conducted in a crossed bed reactor. Results indicate that the temperature and the residence time in the pyrolysis reactor may be optimised. Indeed, it is found that the maximum specific surface of the end product is obtained for pyrolysis processes conducted at a temperature of $400{ }^{\circ} \mathrm{C}$ for a time period of $1 \mathrm{~h}$.
\end{abstract}

Keywords: Wood; Activated carbon; Phosphoric acid; Pyrolysis; Thermogravimetric analysis; Crossed bed reactor

\section{Introduction}

Activated carbons are used in many industrial applications, such as water treatment, separation of gases, refrigeration [1] and gas storage [2,3]. Activated carbons are usually produced from carbon-based substances, such as wood and crop residues. The substance is either processed physically or chemically. In the physical activation process, the carbon-based substance is first pyrolysed and then activated under water vapour or carbon dioxide atmosphere in order to increase its specific surface over $1000 \mathrm{~m}^{2} / \mathrm{g}$. On the other hand, for the chemical activation process, the precursor is first impregnated with a chemical agent before it is pyrolysed. The produced char must then be thoroughly washed in order to rid it from residual impurities.

In the present work, the pyrolysis of wood impregnated with phosphoric acid is examined. The objective of the study is twofold. First, a mathematical model for the pyrolysis process is proposed and validated with experimental data. Second,

\footnotetext{
* Corresponding author. Tel.: +33563493241; fax: +33563493243.

E-mail address: ahmedhar@enstimac.fr (I. Ahmed Hared).
}

laboratory experiments are carried out in a crossed bed reactor in order to study the effect of the residence time and of the pyrolysis temperature on the specific surface area of the produced activated carbons.

\section{Experimental procedure}

Pine wood is the material under investigation here. Prior to their analysis, the wood samples are ground to particles less than $1 \mathrm{~mm}$ in diameter. Their content analysis is summarized in Table 1.

The moisture (air at $105^{\circ} \mathrm{C}$ ), the volatiles (pyrolysis in nitrogen at $900{ }^{\circ} \mathrm{C}$ ) and the ashes content (combustion at $815^{\circ} \mathrm{C}$ ) were determined in accordance with the NF-M03-002, NF-M03003 and NF-M03-004 standard norms, respectively, while the ultimate analysis was carried out using a NA 2100 Carlo Erba analyser. To study the kinetics of pyrolysis, the wood samples were soaked in phosphoric acid (85\%) for several days. The phosphoric acid to wood ratio, i.e., the ratio of the mass of acid to the mass of wood was maintained at 1.5. This ratio was retained as it ensures complete soaking of the precursor [5].

Next, thermogravimetric analyses were conducted to determine the kinetics parameters. Mass samples from 
Table 1

Wood analysis

\begin{tabular}{lrlr}
\hline Proximate analysis (wt.\% basis) & Ultimate analysis (wt.\%) \\
\hline Moisture & 7.74 & Carbon & 46.18 \\
Ashes & 0.45 & Hydrogen & 5.86 \\
Volatile matter $^{\text {Fixed carbon }}{ }^{\mathrm{a}}$ & 78.09 & Nitrogen & 0.44 \\
& 13.72 & Oxygen $^{\mathrm{a}}$ & 47.52 \\
\hline
\end{tabular}

${ }^{\text {a }}$ Calculated by difference.

$10 \mathrm{mg}$ to $20 \mathrm{mg}$ were pyrolysed in a nitrogen atmosphere and weighted with a TGA-DSC 111 SETARAM thermal balance.

The effect of the operating conditions on the porosity of the soaked wood was investigated using a crossed bed reactor (Fig. 1). Each sample, $24 \mathrm{~mm}$ in diameter and $22 \mathrm{~mm}$ in height, was encapsulated in a quartz container with sintered glass at the bottom. The reactor and the external quartz tube were preheated without the internal quartz tube. The sample was then inserted in the internal quartz tube and placed inside the external quartz tube. After a heating period varying from $6 \mathrm{~min}$ to $15 \mathrm{~min}$, the pyrolysis was carried out at a constant temperature ranging between $250{ }^{\circ} \mathrm{C}$ and $600{ }^{\circ} \mathrm{C}$. Afterwards, the sample was thoroughly washed in hot water for $72 \mathrm{~h}$ and dried at $105{ }^{\circ} \mathrm{C}$ for 24 additional hours. Finally, the porosity of the activated carbon was determined with a Micromeritics ASAP 2010 that uses liquid nitrogen.

\section{Results and discussion}

\subsection{Experiments}

Experiments were carried out for two different heating rates. In experiment \#1, the heating rate was set at $10^{\circ} \mathrm{C} / \mathrm{min}$ while for experiment \#2 it was set at $20^{\circ} \mathrm{C} / \mathrm{min}$. In both cases, the final steady state temperature is $800{ }^{\circ} \mathrm{C}$. Fig. 2 illustrates the

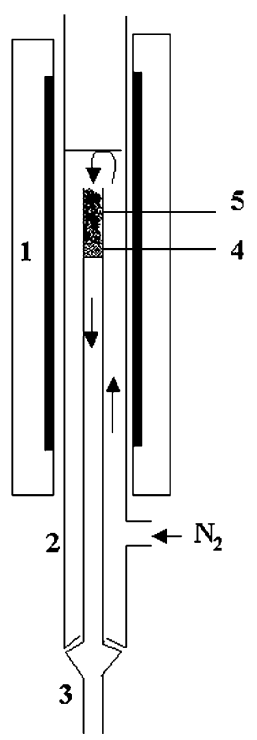

Fig. 1. Vertical quartz reactor with crossed bed. (1) Electrical furnace, (2) external quartz tube, (3) internal quartz tube, (4) sintered quartz and (5) sample. time evolution of the samples for both experiments. Examination of these figures clearly indicates two main peaks in the mass loss. The temperature at which these peaks occur is dependent upon the heating rate. The first peak arises at a temperature between $150{ }^{\circ} \mathrm{C}$ and $200{ }^{\circ} \mathrm{C}$. It results from the drying and the pyrolysis of the sample. Indeed, for wood impregnated with phosphoric acid, light gases, such as carbon monoxide, carbon dioxide and methane are released at a relatively low temperature $\left(\sim 100{ }^{\circ} \mathrm{C}\right)$ [5]. The second peak, which is observed at a much higher temperature $\left(\sim 700{ }^{\circ} \mathrm{C}\right)$, exemplifies the chemical conversion of phosphoric acid and of $\mathrm{P}_{2} \mathrm{O}_{5}$. This peak cannot be attributed to the pyrolysis of wood since the thermal degradation of pine wood is terminated at a temperature of $380{ }^{\circ} \mathrm{C}$ [6].

\subsection{Modeling}

Due to its complexity, the kinetics of the pyrolysis process of wood is often modeled as a series of simple chemical reactions [7]. For instance, Turner et al. [8] have developed a model that rests on three primary reactions for the char, the tar and the gas, respectively, and secondary reactions for the polymerization of tar into char and for the cracking of tar. On the other hand, Koufopanos et al. [9] have proposed to model the pyrolysis of wood as the sum of the pyrolysis of its main components, i.e., cellulose, hemicellulose and lignin. Their model could not, however, be easily transposed to the present case since the kinetics of reaction for the pyrolysis process of impregnated wood with phosphoric acid is not fully understood. In fact, to the authors' knowledge, only one study has been reported in the open literature on the modeling of the pyrolysis of lignocellulosic materials activated with phosphoric acid [4]. When applied to the pyrolysis of the wood impregnated with phosphoric acid, the model leads to the following reaction scheme:

$$
\begin{aligned}
& \text { Wood }+\mathrm{H}_{3} \mathrm{PO}_{4} \rightarrow \mathrm{WP}+\mathrm{H}_{2} \mathrm{O} \\
& \mathrm{H}_{2} \mathrm{O}(\text { liquid }) \rightarrow \mathrm{H}_{2} \mathrm{O}(\text { gas }) \\
& \mathrm{H}_{3} \mathrm{PO}_{4} \rightarrow \frac{1}{2}\left(\mathrm{P}_{2} \mathrm{O}_{5}+3 \mathrm{H}_{2} \mathrm{O}\right) \\
& \mathrm{P}_{2} \mathrm{O}_{5} \text { (liquid) } \rightarrow \mathrm{P}_{2} \mathrm{O}_{5} \text { (gas) } \\
& \mathrm{WP} \rightarrow \alpha \text { char }+(1-\alpha) \text { volatiles } \\
& \text { Char } \rightarrow \text { gas }
\end{aligned}
$$

Eq. (1) represents the reaction between wood and phosphoric acid. According to Montané et al. [4], this reaction occurs at room temperature and is completed within an hour. In fact, phosphoric acid reacts as soon as it is mixed with wood. The reaction does not lead however to a loss of mass. ${ }^{13} \mathrm{C}$ NMR analyses of oak impregnated with phosphoric acid have shown that there are detectable changes in the composition of wood biopolymers and in the dimension of the wood matrix at a temperature of $50{ }^{\circ} \mathrm{C}$ [5].

Eq. (2) is the evaporation of water contained in the sample. Eq. (3) exemplifies the chemical transformation of phosphoric 


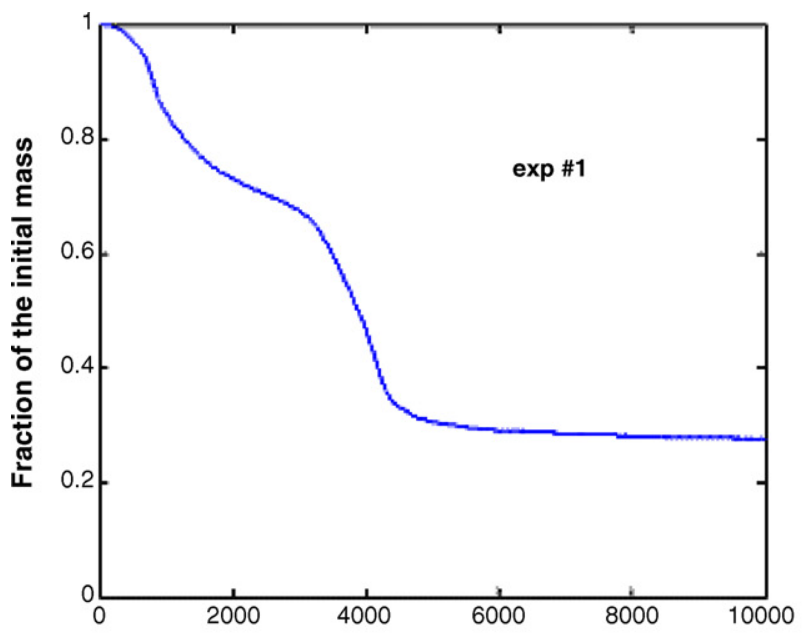

(a)

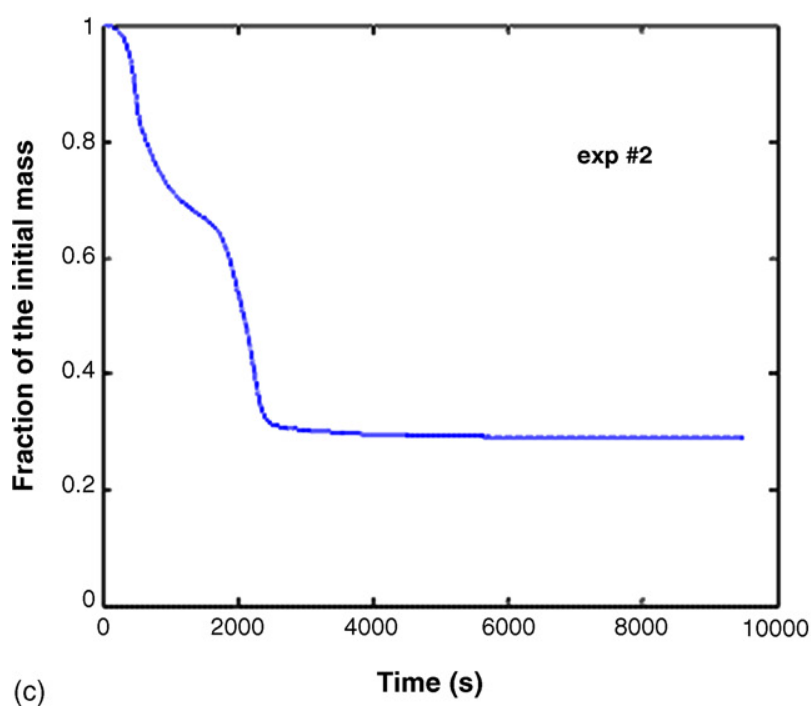

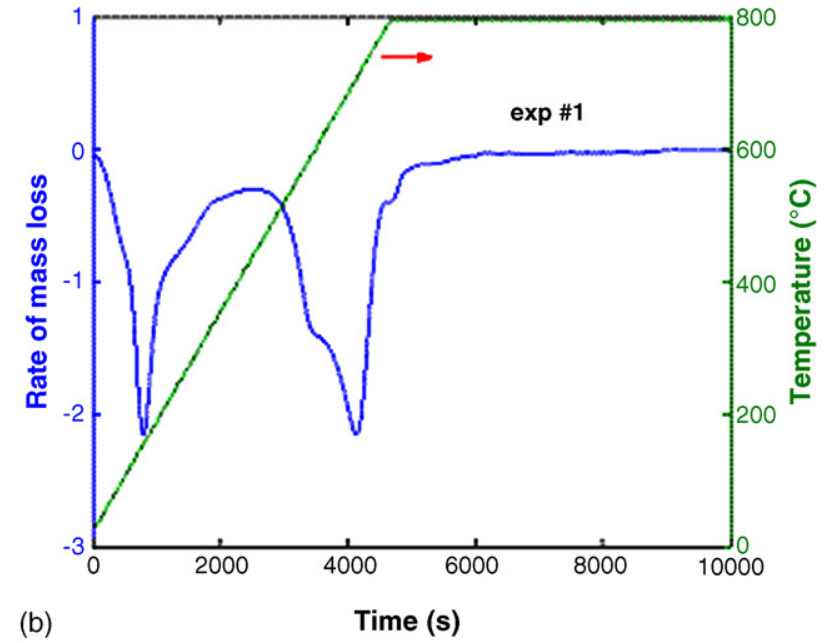

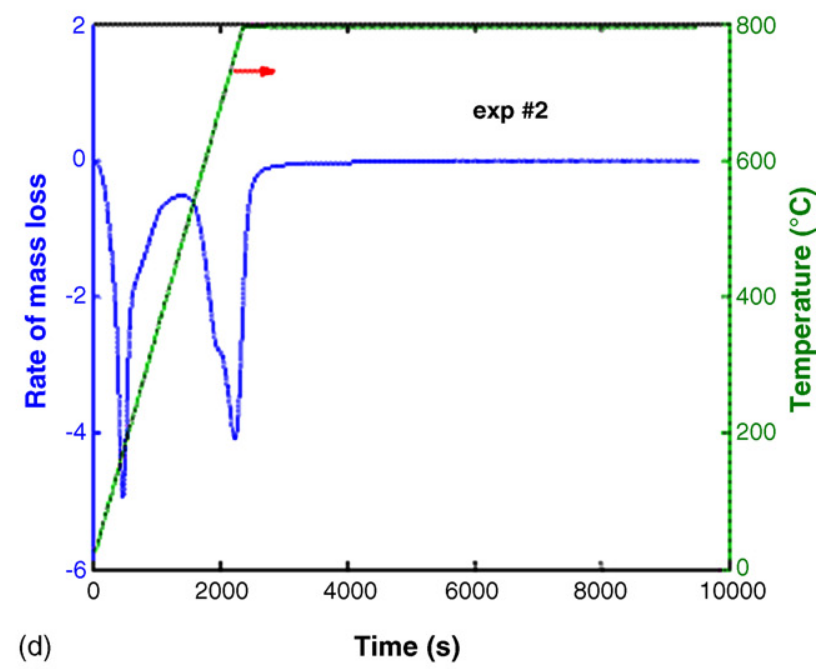

Fig. 2. TG and DTG curves for experiments at $10{ }^{\circ} \mathrm{C} / \mathrm{min}(\mathrm{a}-\mathrm{b})$ and $20{ }^{\circ} \mathrm{C} / \mathrm{min}(\mathrm{c}-\mathrm{d})$.

acid into $\mathrm{P}_{2} \mathrm{O}_{5}$ via water desorption. As the temperature increases, phosphoric acid is converted to several species, such as pyrophosphoric acid $\left(\mathrm{H}_{4} \mathrm{P}_{2} \mathrm{O}_{7}\right)$ and polyphosphoric acid $\left(\mathrm{H}_{n+2} \mathrm{P}_{n} \mathrm{O}_{3 n+1}\right)$ by condensation and dehydration and eventually $\mathrm{P}_{2} \mathrm{O}_{5}[4,10]$. As a result, reaction (2) is a simplified formulation of a series of more complex chemical reactions.

Eq. (4) stands for the evaporation of $\mathrm{P}_{2} \mathrm{O}_{5}$. This component vaporizes at a temperature between $580{ }^{\circ} \mathrm{C}$ and $585{ }^{\circ} \mathrm{C}$ (second peak observed near $700{ }^{\circ} \mathrm{C}$ in the DTG curves of Fig. 2) [11].

Eq. (5) illustrates the pyrolysis of the wood-phosphoric acid complex WP into char and volatiles. Finally, the release of light gases from char is taken into account by Eq. (6).

The first order rate equations for the pyrolysis of impregnated wood with phosphoric acid may then be stated as follows:

$\frac{\mathrm{d} y_{\mathrm{H}_{2} \mathrm{O}}}{\mathrm{d} t}=-k_{2} \times y_{\mathrm{H}_{2} \mathrm{O}}+\frac{3}{2} \times k_{3} \frac{\mathrm{MW}_{\mathrm{H}_{2} \mathrm{O}}}{\mathrm{MW}_{\mathrm{H}_{3} \mathrm{PO}_{4}}} \times y_{\mathrm{H}_{3} \mathrm{PO}_{4}}$

$\frac{\mathrm{d} y_{\mathrm{H}_{3} \mathrm{PO}_{4}}}{\mathrm{~d} t}=-k_{3} \times y_{\mathrm{H}_{3} \mathrm{PO}_{4}}$ $\frac{\mathrm{d} y_{\mathrm{P}_{2} \mathrm{O}_{5}}}{\mathrm{~d} t}=-k_{4} \times y_{\mathrm{P}_{2} \mathrm{O}_{5}}+\frac{1}{2} \times k_{3} \frac{\mathrm{MW}_{\mathrm{P}_{2} \mathrm{O}_{5}}}{\mathrm{MW}_{\mathrm{H}_{3} \mathrm{PO}_{4}}} \times y_{\mathrm{H}_{3} \mathrm{PO}_{4}}$

$\frac{\mathrm{d} y_{\mathrm{WP}}}{\mathrm{d} t}=-k_{5} \times y_{\mathrm{WP}}$

$\frac{\mathrm{d} y_{\text {char }}}{\mathrm{d} t}=\beta \times k_{5} \times y_{\mathrm{WP}}-k_{6} \times y_{\text {char }}$

$y=y_{\mathrm{H}_{2} \mathrm{O}}+y_{\mathrm{H}_{3} \mathrm{PO}_{4}}+y_{\mathrm{P}_{2} \mathrm{O}_{5}}+y_{\mathrm{WP}}+y_{\text {char }}$

with

$\beta=\alpha \frac{\mathrm{MW}_{\text {char }}}{\mathrm{MW}_{\mathrm{WP}}}$

and

$k_{i}=A 0_{i} \times \exp \left(-\frac{E_{i}}{\mathrm{RT}}\right)$

$y_{i}$ is the normalized mass of species $i$ and $\mathrm{MW}_{i}$ is its molar mass. The initial mass fractions for each species were estimated from 
the moisture content of the wood and the aqueous solution of phosphoric acid. When a wood sample is soaked into phosphoric acid, a fraction $\beta^{\prime}$ of phosphoric anhydrous binds with wood to form a wood-phosphoric acid complex WP. The remaining fraction $1-\beta^{\prime}$ represents the excess of phosphoric acid. The initial mass of the complex WP is then estimated by adding the mass of wood to the mass of bound acid that is $\beta^{\prime} \times$ mass of anhydrous $\mathrm{H}_{3} \mathrm{PO}_{4}$. Moreover, the total mass of water is the sum of the moisture content of the wood to that of the water resulting from the chemical reaction with the acid. Therefore, the initial mass fractions for the rate Eqs. (7), (8) and (10) are, respectively,

$y_{\mathrm{H}_{2} \mathrm{O}, 0}=\frac{\text { mass of water }+ \text { mass of moisture }}{\text { total mass of the sample }}$

$y_{\mathrm{H}_{3} \mathrm{PO}_{4}, 0}=\frac{\left(1-\beta^{\prime}\right) \times \text { mass of anhydrous } \mathrm{H}_{3} \mathrm{PO}_{4}}{\text { total mass of the sample }}$

$y_{\mathrm{WP}, 0}=\frac{\text { mass of dry wood }+\beta^{\prime} \times \text { mass of anhydrous } \mathrm{H}_{3} \mathrm{PO}_{4}}{\text { total mass of the sample }}$

Ten Arrhenius parameters $\left(A 0_{i}\right.$ and $\left.E_{i}\right)$ and two additional constants $\beta$ and $\beta^{\prime}$ were estimated from a least square minimization procedure between the measurements and the predictions, i.e.,

$\mathrm{OF}=\sum_{i=1}^{p} \sum_{j=1}^{n}\left(y_{i j}^{\mathrm{cal}}-y_{i j}^{\exp }\right)^{2}$

$p$ is the number of performed experiments and $n$ is the number of data retained for the calculations. In the present study, $p=2$ and $n=88$.

As an example, Fig. 3 shows that the measured and the predicted time variation of the mass fractions for both heating rates are in excellent agreement. The corresponding optimal parameters are summarized in Table 2.

In these experiments, the activation energy for the drying process (Eq. (2)) was estimated at $30.8 \mathrm{~kJ} / \mathrm{mol}$, a value comparable to that found for the drying of wood, $26 \mathrm{~kJ} / \mathrm{mol}$ [12] and for the drying of lignin, $24 \mathrm{~kJ} / \mathrm{mol}$ [4].

The activation energy for the transformation of phosphoric acid into $\mathrm{P}_{2} \mathrm{O}_{5}$ (Eq. (3)) was measured at $71.5 \mathrm{~kJ} / \mathrm{mol}$. This value is similar to that reported in the kinetic modeling of lignin impregnated with phosphoric acid [4]. To the authors' knowledge, no other data for the activation energy of lignocellulosic materials impregnated with phosphoric acid are available in the open literature.

The activation energy for the evaporation of $\mathrm{P}_{2} \mathrm{O}_{5}$ (Eq. (4)) was determined at $102.5 \mathrm{~kJ} / \mathrm{mol}$ and that for the pyrolysis of the complex WP at $32.8 \mathrm{~kJ} / \mathrm{mol}$ (Eq. (5)). The latter is slightly less than that reported for the pyrolysis of non impregnated wood which, in general, ranges from $56 \mathrm{~kJ} / \mathrm{mol}$ to $173 \mathrm{~kJ} / \mathrm{mol}$ [6]. Finally, the activation energy found for the release of light gas (Eq. (6)) was $61.5 \mathrm{~kJ} / \mathrm{mol}$.

The numerical predictions reported in Fig. 3 also reveal the time evolution of the different chemical species during pyrolysis. It is seen that the drying of the wood sample is
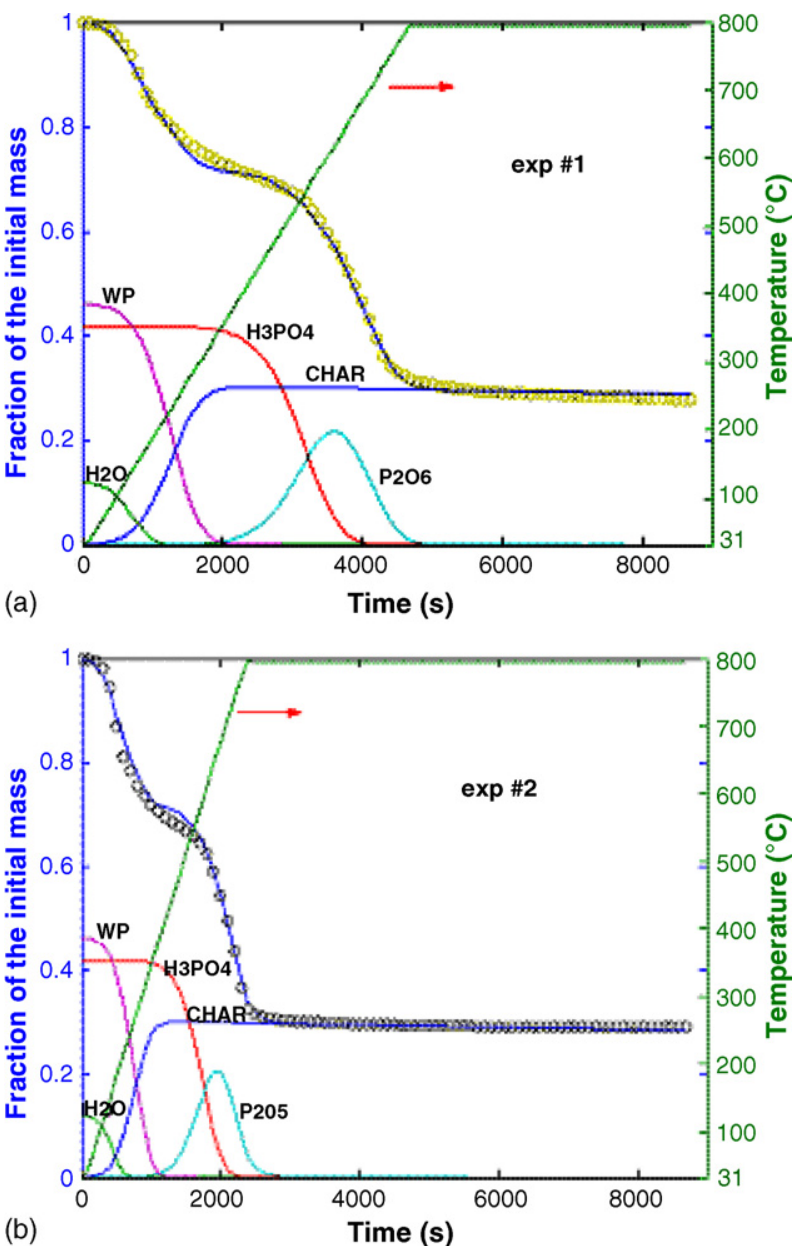

Fig. 3. Comparison between experimental TG curve and predicted one.

completed at a temperature of roughly $230{ }^{\circ} \mathrm{C}$ while the pyrolysis of the complex WP is over when the temperature of the reactor reaches $400{ }^{\circ} \mathrm{C}$. The pyrolysis of phosphoric acid starts at approximately $300{ }^{\circ} \mathrm{C}$ and continues for temperatures up to $700{ }^{\circ} \mathrm{C}$. It is also observed that the effect of the release of light gases from char (Eq. (6)) on the evolution of the char mass fraction is insignificant.

\subsection{Porosity and specific surface}

Aside from the chemical transformations that take place during the pyrolysis process, the wood-phosphoric acid complex WP also undergoes morphological as well as dimensional changes. Two of the most influential textural parameters that characterize activated carbon are its porosity

Table 2

Optimal values for the parameters

\begin{tabular}{llclll}
\hline Reaction & $A 0_{i}\left(\mathrm{~s}^{-1}\right)$ & $E_{i}(\mathrm{~kJ} / \mathrm{mol})$ & $\beta$ & $\beta^{\prime}$ & Minimum OF \\
\hline$(2)$ & $236 \times 10^{-1}$ & 30.8 & 0.65 & 0.23 & $1.389 \times 10^{-2}$ \\
$(3)$ & $614 \times 10^{-1}$ & 71.5 & & & \\
$(4)$ & $6673 \times 10^{-1}$ & 102.5 & & & \\
$(5)$ & $553 \times 10^{-2}$ & 32.8 & & & \\
$(6)$ & $824 \times 10^{-3}$ & 61.5 & & & \\
\hline
\end{tabular}




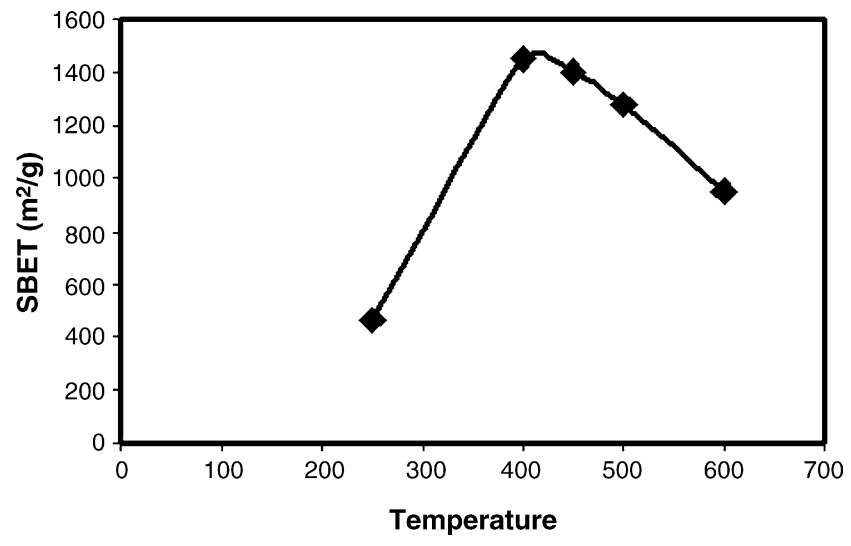

Fig. 4. Specific surface area vs. temperature.

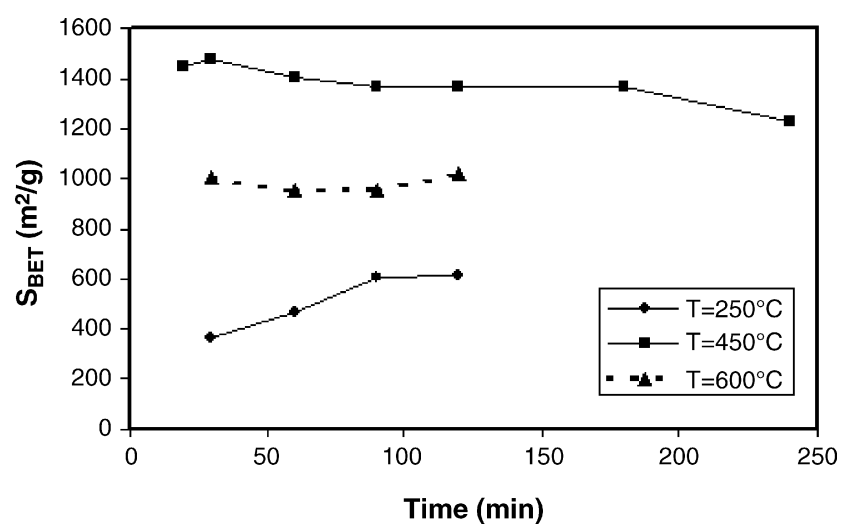

Fig. 5. Specific surface area vs. time.

and its specific surface [5]. These properties are dependent on the phosphoric acid to wood ratio, the activation temperature and the time duration of the pyrolysis process [5,10,13-17].

In the present study, the effect of the temperature and of the time duration of the pyrolysis process was examined.

Fig. 4 exemplifies the effect of the temperature on the specific surface of the activated carbon resulting from the pyrolysis of impregnated wood. In these experiments, the activation time period was fixed at $1 \mathrm{~h}$. It is seen that a maximum is reached at a temperature of $400{ }^{\circ} \mathrm{C}$. Other studies available in the literature reported maxima in the specific surface for operating temperatures ranging from $350{ }^{\circ} \mathrm{C}$ to $500{ }^{\circ} \mathrm{C}$ for lignocellulosic materials and bituminous coal [5,10,13-17].

The trend observed in Fig. 4 may be explained by the fact that phosphoric acid acts as a catalyst for breaking down large molecules, such as cellulose, hemicellulose and lignin in the wood. The acid also combines with organic matter yielding bridges between phosphates and polyphosphates [5,10]. As a result, the mechanical properties of the material are strengthened and contraction is hindered. For temperatures above $450{ }^{\circ} \mathrm{C}$, however, these bindings break down and consequently the material contracts and its porosity diminishes [5].

The effect of the time duration of the pyrolysis process on the resulting porosity of the activated carbon was also examined. The results for the time evolution of the specific surface for three different process temperatures, i.e., $250{ }^{\circ} \mathrm{C}$, $450{ }^{\circ} \mathrm{C}$ and $600{ }^{\circ} \mathrm{C}$, are depicted in Fig. 5. It is seen that the maximum porosity is obtained for a process temperature of $450{ }^{\circ} \mathrm{C}$ and a residence time of $30 \mathrm{~min}$. For time periods above $30 \mathrm{~min}$, the results indicate that the porosity diminishes slightly. From an industrial point of view, these findings are of the utmost importance as they suggest that pyrolysis reactors may be operated in such a way as to simultaneously minimize their energy consumption and maximize the quality of the end product.

\section{Conclusion}

The kinetics for the pyrolysis of impregnated wood for the production of activated carbon was investigated. Based on laboratory experiments performed with a thermogravimetric apparatus, a mathematical model for the kinetics of the pyrolysis process was proposed and validated.

The effect of the temperature and of the time duration of the pyrolysis process on the specific surface of the activated carbon was then investigated experimentally, using a crossed bed reactor. Results indicate that the temperature and the residence time in the pyrolysis reactor may be optimised. It was found that the maximum specific surface of the produced activated carbon is obtained for pyrolysis processes conducted at a temperature of $400{ }^{\circ} \mathrm{C}$ and for a time period of $1 \mathrm{~h}$.

\section{Acknowledgements}

The authors are grateful to the Ministère de l'économie, des finances et de l'industrie de France and to the National Sciences and Engineering Research Council of Canada for their financial support.

\section{References}

[1] G. Cacciola, G. Restuccia, L. Mercadante, Carbon 33 (1995) 1205-1210.

[2] M. Molina-Sabio, C. Almansa, F. Rodrıguez-Reinoso, Carbon 41 (2003) 2113-2119.

[3] J.A.F. Macdonald, D.F. Quinn, Carbon 34 (1996) 1103-1108.

[4] D. Montané, V. Torné-Fernandez, V. Fierro, Chem. Eng. J. 106 (2005) 112.

[5] M. Jagtoyen, F. Derbyshire, Carbon 36 (1998) 1085-1097.

[6] M.G. Grønli, G. Várhegyi, C. Di Blasi, Ind. Eng. Chem. Res. 41 (2002) 4201-4208.

[7] C. Branca, C. Di Blasi, J. Anal. Appl. Pyrolysis (2003) 207-219.

[8] F. Thurner, U. Mann, Ind. Eng. Chem. Proc. Des. Dev. 20 (1981) 482.

[9] C.A. Koufopanos, G. Maschio, A. Lucchesi, Can. J. Chem. Eng. 67 (1989) 75.

[10] H. Bennadi, Ph.D. Thesis, Université d'Orléans, 1995.

[11] D.R. Lide, Handbook of Chemistry and Physics, CRC Press, 2006.

[12] B. Peters, C. Bruch, J. Anal. Appl. Pyrolysis 70 (2003) 233-250.

[13] J. Laine, A. Calafat, M. Labady, Carbon 27 (1989) 191-195.

[14] A. Ahmadpour, D.D. Do, Carbon 35 (1997) 1723-1732.

[15] M.C. Baquero, L. Giraldo, J.C. Moreno, F. Suarez-Garcia, A. MartinezAlonso, J.M.D. Tascon, J. Anal. Appl. Pyrolysis 70 (2003) 779-784.

[16] F. Suarez-Garcia, A. Martinez-Alonso, J.M.D. Tascon, J. Anal. Appl. Pyrolysis 63 (2002) 283-301.

[17] H. Teng, T.S. Yeh, L.Y. Hsu, Carbon 36 (1998) 1387-1395. 